\title{
Inhibitory effect of somatostatin on gastric acid secretion and serum gastrin in dogs with and without duodenogastric reflux
}

\author{
W E G THOMAS \\ From the Department of Surgery, Bristol Royal Infirmary, Bristol
}

SUMMARY The hypersecretion of gastric acid in response to pentagastrin, caused by duodenal reflux, was tested in dogs. An infusion of $0.25 \mu \mathrm{g} / \mathrm{kg} / \mathrm{h}$ was found to restore the raised responses seen in the reflux dogs to control levels. Somatostatin was a strong inhibitor of pentagastrin-stimulated acid secretion and of gastrin release, but it was a weak inhibitor of histamine. These studies suggest that somatostatin may have played a part in acid homeostasis.

Dogs with surgically-produced duodenal reflux hypersecrete gastric acid in response to a pentagastrin simulus, ${ }^{1}$ but not to histamine. ${ }^{2}$ The specificity of that response argues against a trophic effect of hypergastrinaemia caused by alkaline reflux, but it does appear to be an effect produced by the mixture of bile and pancreatic juice as it does not occur with bile diversion alone. Duodenal reflux also causes hypergastrinaemia in response to a standard meal, although fasting levels are unchanged. ${ }^{3}$

These findings could be explained by suppression of a naturally-occurring substance produced by the antrum that would suppress gastrin release and inhibit the acid response to pentagastrin, but not to histamine. This proposed inhibitor would itself be activated in an acid milieu and suppressed in an alkaline milieu, and, as somatostatin fulfils these criteria, its effects were studied in the same dogs.

\section{Methods}

Adult litter-mate beagles were used to achieve uniformity of weight $(11.3 \mathrm{~kg} \pm 1.8 \mathrm{SD})$ and were prepared as previously described. ${ }^{2}$ They were allocated at random into two groups, each of five animals: (1) a control group; (2) dogs with duodenal reflux, produced by dividing the duodenum distal to the entry of the common bile duct and pancreatic ducts, and anastomosing the proximal duodenum to the upper lesser curve (Fig. 1). Intestinal continuity was restored by a posterior gastroduodenostomy.

Received for publication 3 July 1980
All dogs in both groups were equipped with a Gregory gastrostomy cannula.

At least one month was allowed after surgery before any secretion tests were undertaken, and for the duration of the trial the dogs were kept in the same environmental surroundings and fed on a standard diet of New Bounce and dog biscuits. Before any test was undertaken, it was ensured that the animal was in good health and all tests were performed with the dog fully conscious and with no sedation.

Before any actual test was performed, each dog had been trained to stand still in the restraining apparatus for periods of up to eight hours, which they all tolerated extremely well, the general temperament of the beagle being ideally suited for this type of work.

At the beginning of each experiment, basal secretion was collected by gravity from the gastrostomy cannula for a period of one hour, and the volume measured and acid content determined. Intravenous access was obtained using two separate peripheral venous cannulae and all infusions used during these studies were given by slow constant intravenous infusions in a solution of $0.9 \%$ sodium chloride, using a Multispeed Precidor infusion pump. Solutions were made up freshly on the day of each experiment.

Each dog was fasted for at least 18 hours before any experiment, and a minimum of 36 hours was allowed to elapse between any two consecutive tests. No dog was studied more than three times in any one week.

Each of the following experiments was performed 


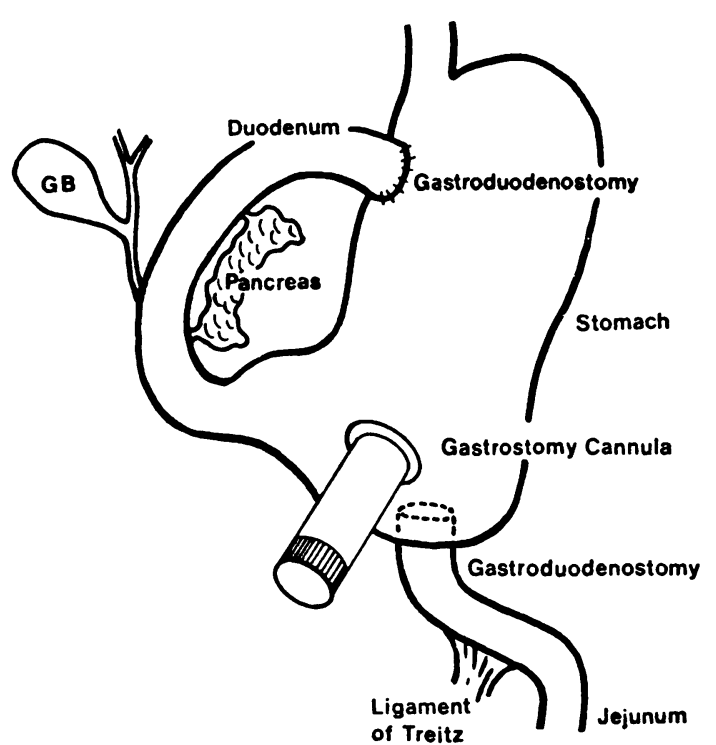

Fig. 1 The duodenal reflux preparation.

in duplicate. Dose response inhibition by somatostatin was studied during a constant infusion of either pentagastrin $(8.0 \mu \mathrm{g} / \mathrm{kg} / \mathrm{h})$ or histamine $(80 \mu \mathrm{g} / \mathrm{kg} / \mathrm{h})$. In addition, dose response curves to both pentagastrin and histamine were determined with and without constant infusions of somatostatin at $0.25 \mu \mathrm{g} / \mathrm{kg} / \mathrm{h}$ and $0.5 \mu \mathrm{g} / \mathrm{kg} / \mathrm{h}$ or $2.0 \mu \mathrm{g} / \mathrm{kg} / \mathrm{h}$. Each dose was administered for one hour to allow a stable level of acid response to be achieved. Acid output (mmol) was calculated for each 15 minute period and values for the second half-hour at each dose rate analysed.

The effect of a low dose infusion of somatostatin $(0.25 \mu \mathrm{g} / \mathrm{kg} / \mathrm{h})$ on the gastrin response to a standard meal was also assessed in each of the five dogs with duodenal reflux.

Statistical significance was assessed using Wilcoxon's rank sum test, which avoids the assumption of normally-distributed values in the population sampled.

\section{Results}

Throughout this study, all the dogs remained well and showed no unwanted effects from the infusion of somatostatin.

Somatostatin strongly inhibited pentagastrinstimulated acid secretion in both groups of dogs, even at the lowest dose of $0.25 \mu \mathrm{g} / \mathrm{kg} / \mathrm{h}$ (Fig. 2 (top)). The reflux dogs again produced a greater acid response to pentagastrin than the control dogs, but $0 \cdot 25 \mu \mathrm{g} / \mathrm{kg} / \mathrm{h}$ of somatostatin reduced this response to the same level as the control group's response to pentagastrin alone. In both groups of dogs, the inhibitory effect was proportional to the dose of somatostatin. Virtually complete inhibition of acid secretion occurred at a dose of $8.0 \mu \mathrm{g} / \mathrm{kg} / \mathrm{h}$ of somatostatin. The difference in acid output and percentage inhibition between the reflux and control dogs was most marked at doses of 0.25 and 0.5 $\mu \mathrm{g} / \mathrm{kg} / \mathrm{h}$ of somatostatin $(\mathrm{P}<0.05)$, while at higher doses there was no difference between these two curves. An exponential function appears to fit the data well for this experiment and, assuming that the differential response was due to the suppression of the action of somatostatin in the reflux group by the alkaline milieu, then the delay factor can be calculated for the control response curve. This factor would represent the amount of somatostatin activity that was already present in the control dogs, and was
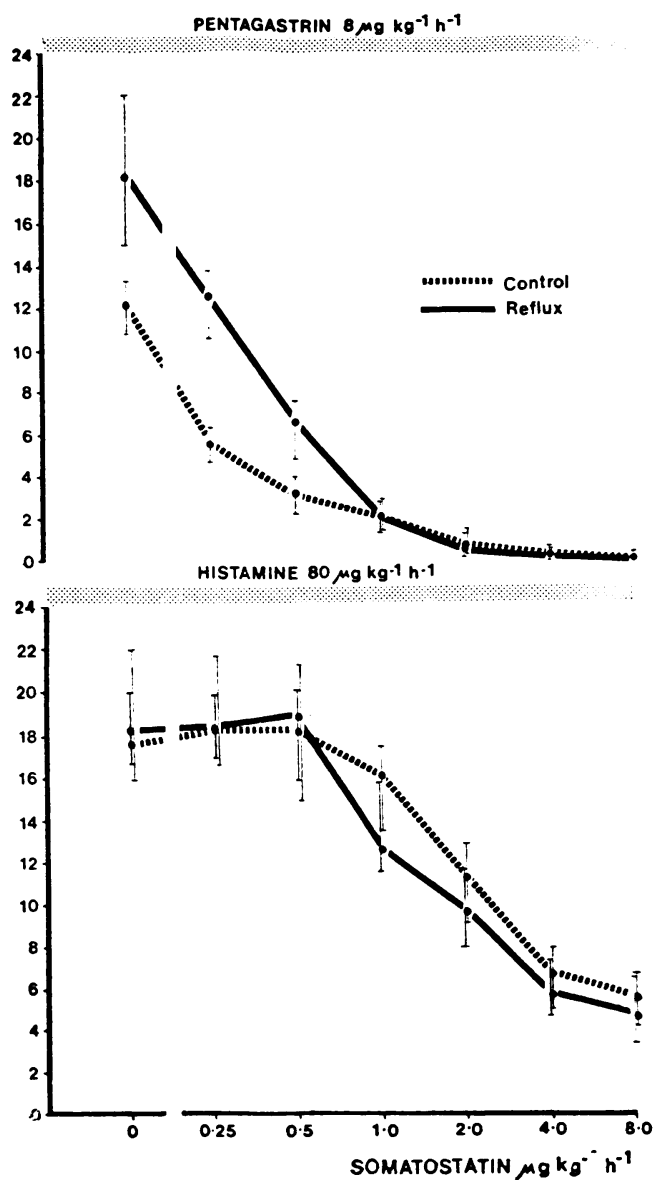

Fig. 2 Median dose response inhibition to somatostatin (top) with $8 \mu \mathrm{g} / \mathrm{kg} / \mathrm{h}$ pentagastrin, (bottom) with $80 \mu \mathrm{g} / \mathrm{kg} / \mathrm{h}$ histamine. 


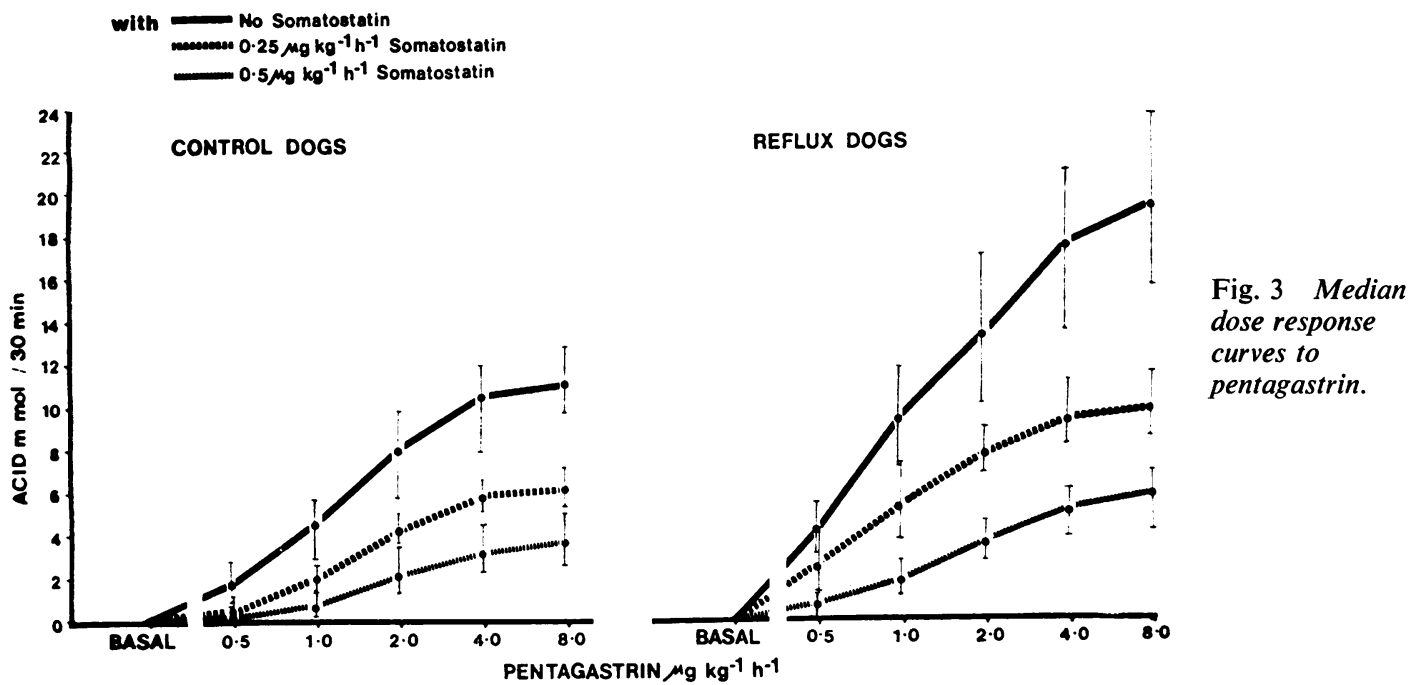

calculated to be equivalent to an infusion of 0.249 $\mu \mathrm{g} / \mathrm{kg} / \mathrm{h}$. Thus these results are consistent with this amount of somatostatin activity being present in the control dogs and suppressing the acid response to pentagastrin, while this activity would be suppressed by alkaline reflux in the reflux dogs. However, it must be stressed that this is only a hypothesis and is as yet unconfirmed.

Histamine stimulated acid secretion was far more resistant to the inhibitory powers of somatostatin (Fig. 2 (bottom)). No inhibition was demonstrated until the dose rate of somatostatin was increased to $1.0 \mu \mathrm{g} / \mathrm{kg} / \mathrm{h}$ and in this case there was no significant difference between the acid responses or the per- centage inhibition of the two groups of dogs.

Dose response curves to pentagastrin again demonstrated the hypersecretion of acid produced by the reflux dogs (Fig. 3). However, this hypersecretion can be abolished by a concomitant infusion of $0.25 \mu \mathrm{g} / \mathrm{kg} / \mathrm{h}$ somatostatin. Somatostatin inhibition appeared to depress the curve, rather than producing a shift to the right, suggesting that it acts via a non-competitive mechanism. This method of action was confirmed by kinetic analysis (Fig. 4), which demonstrated that somatostatin markedly reduced the calculated maximal response ( $\mathrm{V}$ max), with no significant difference in $\mathrm{Km}$.

Dose response curves to histamine, however,

$\checkmark$ MAX ICALCULATEO MAXIMAL RESPONSEI IS GIVEN BY VERTICAL INTERCEPT KM/D50 IS GIVEN BY THE SLOPE
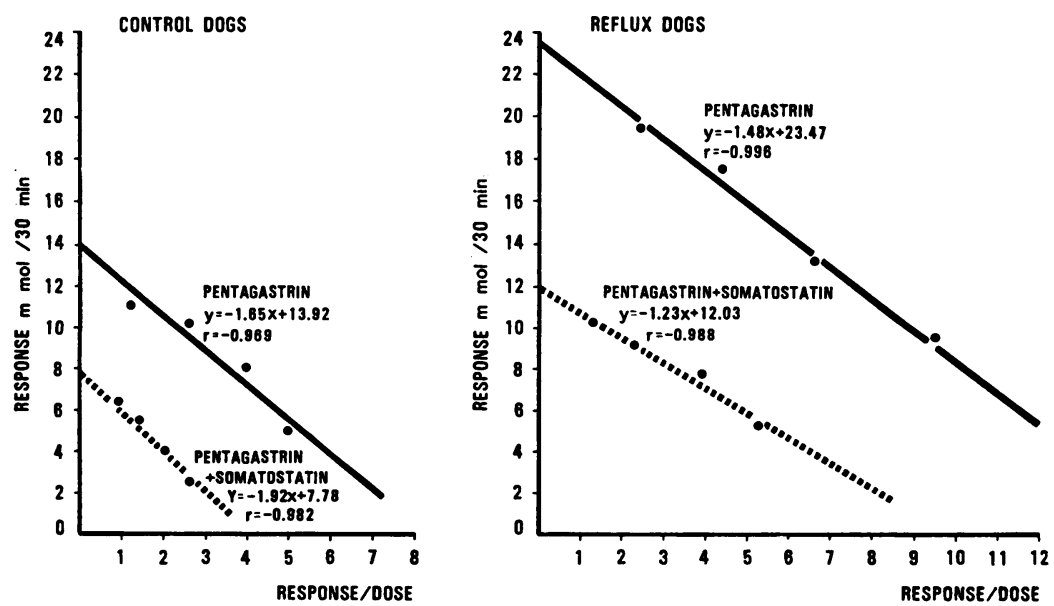

Fig. 4 Linear plots of gastric acid output against ratio of response/dose. 
wh Wh Somatostatin

$0.25 \mathrm{Mg} \mathrm{kg}^{-1} \mathrm{~h}^{-1}$ Somatostatin

$2.0 \mathrm{mg} \mathrm{kg}^{-1} \mathrm{~h}^{-1}$ Somatostatin

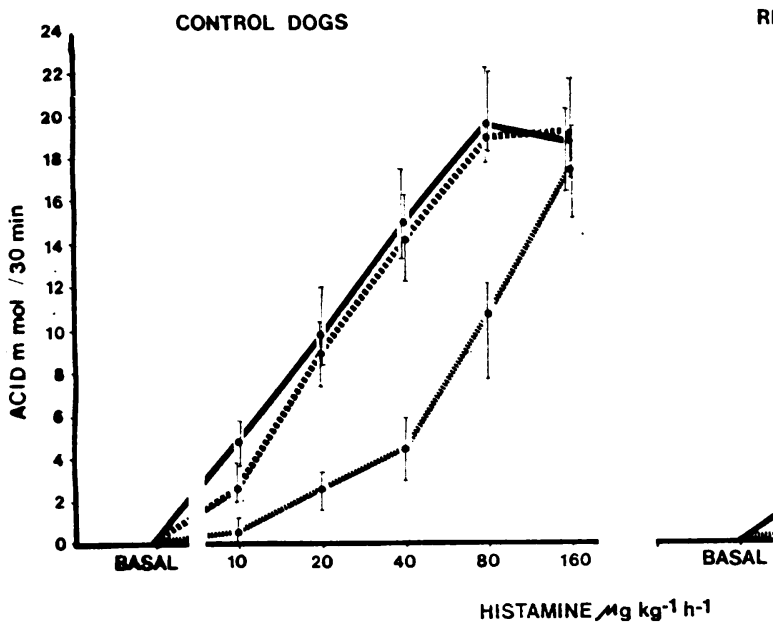

REFLUX DOGS

Fig. 5 Median

dose response

curves to histamine.

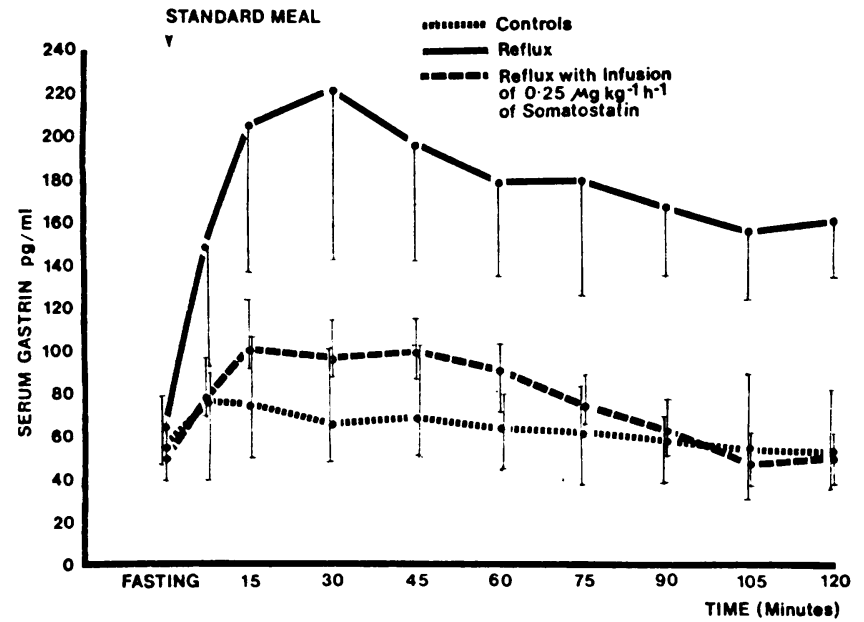

Fig. 6 Median serum gastrin levels after standard meal.

demonstrated different characteristics from those with pentagastrin (Fig. 5). The maximum response in both groups was seen with $80 \mu \mathrm{g} / \mathrm{kg} / \mathrm{h}$ but 0.25 $\mu \mathrm{g} / \mathrm{kg} / \mathrm{h}$ of somatostatin produced no significant difference from the response curve to histamine in either of the groups. However $2.0 \mu \mathrm{g} / \mathrm{kg} / \mathrm{h}$ of somatostatin produced inhibition with a shift of the curve to the right suggesting that, not only are higher concentrations of somatostatin needed to inhibit histamine, but also that somatostatin may inhibit histamine in a different manner to pentagastrin.

A low dose infusion of somatostatin $(0.25 \mu \mathrm{g} / \mathrm{kg} / \mathrm{h})$ also suppressed the postprandial hypergastrinaemia that was seen in the reflux dogs $(P<0.01)$ and virtually restored the response to control levels by suppressing gastrin release (Fig. 6).

\section{Discussion}

Somatostatin (growth-hormone release-inhibiting hormone) is a cyclical tetradecapeptide that was first isolated from the hypothalamus in $1973^{4}$ but more recently has been shown to be present in the $D$ cells of the pancreas and in the gastrointestinal tract. ${ }^{5}$ Indeed, the gastrointestinal tract contains more somatostatin than the brain, ${ }^{6}$ with the highest proportion being found in the antrum of the stomach.? 
The results of this study confirm the findings of other workers that somatostatin is a powerful inhibitor of pentagastrin-stimulated acid secretion ${ }^{8} 9$ and only a moderate inhibitor of histamine stimulated acid secretion. ${ }^{10}$ However, its physiological role in the control of acid secretion remains uncertain.

Somatostatin has now been assayed in antral and portal venous blood in the pig by Gustavsson and Lundqvist $^{11}$ and the levels were found to fall after irrigation of the antrum with alkali or meat extract. Conversely, intragastric $0.1 \mathrm{M} \mathrm{HCl}$ causes degranulation of the $D$ cells of the canine pyloric antrum ${ }^{12}$ that are known to release somatostatin ${ }^{5}$. Moreover, acid introduced into the pyloric antrum of the rat leads to a very transient increase in the amount of somatostatin, demonstrating that antral $\mathrm{D}$ cells respond to a change in $\mathrm{pH} .{ }^{13}$ This effect has now been demonstrated in dogs by Schusdziarra et al..$^{14}$ who found that intragastric acid causes a marked rise in the somatostatin level in antral venous blood, which is reflected 20 minutes later by a smaller rise in the somatostatin level of the inferior vena cava.

Suppression of somatostatin activity by alkalinisation of the antrum from reflux of duodenal contents could therefore explain the results of the hypersecretion of acid that is seen in the dogs with reflux when stimulated with pentagastrin, and the findings of the present study suggest that, in the control dogs, the increased somatostatin activity over the reflux dogs would be equivalent to an infusion of 0.249 $\mu \mathrm{g} / \mathrm{kg} / \mathrm{h}$. In confirmation of this dose, the dose response curves of the reflux dogs to pentagastrin with a concomitant infusion of $0.25 \mu \mathrm{g} / \mathrm{kg} / \mathrm{h}$ are seen to be the same as the control dogs' response to pentagastrin alone, while at that level of somatostatin activity the two groups of dogs respond identically to histamine. Such an infusion also suppresses the raised and prolonged gastrin response to a meal seen in the reflux dogs.

This dose rate is very much smaller than those used by other workers in this field ${ }^{81017}$ and, although one cannot definitely call it 'physiological', it is low enough to suggest that this is a possibility. This is supported by finding that a meal acidified to $\mathrm{pH} 2$ causes a rise in peripheral venous somatostatin-likeimmunoreactivity similar to levels observed when somatostatin is infused at $0.5-0.7 \mu \mathrm{g} / \mathrm{kg} / \mathrm{h} .{ }^{18} 19$

If the raised responses seen in the reflux preparation were due to the suppression of a physiological inhibitory mechanism, then the proposed inhibitory factor would have to fulfil the following criteria: (1) it must be naturally-occurring; (2) it would have to inhibit the effects of gastrin and pentagastrin; (3) it would not inhibit histamine at the doses required to produce its effect against pentagastrin;
(4) it would inhibit the release of gastrin from Gcells; and (5) its inhibitory activity would be suppressed with alkaline reflux.

It can now be seen from the results of this paper and those of other workers ${ }^{51119}$ that somatostatin fulfils all these criteria. These results are therefore consistent with the hypothesis that somatostatin acts as a physiological antral inhibitor that is itself suppressed in the state of alkaline duodenal reflux leading to a hypersecretory state. Somatostatin may therefore play an important role in the homeostasis of gastric acid secretion, a role that is dependent on antral pH.

This work was performed while the author was a Bernard-Sunley Fellow at the Royal College of Surgeons and was supported by the East Anglian Regional Health Authority. The author is indebted to Professor J H Wyllie and Professor D E M Taylor for their helpful criticism and advice, and to Professor $R$ Y Calne who provided facilities in the Department of Surgery, Addenbrookes Hospital, Cambridge. The somatostatin was kindly donated by Ayerst Laboratories.

\section{References}

${ }^{1}$ Thomas WEG. Gastric acid secretion in response to pentagastrin in duodenal reflux and bile diversion. J Physiol 1978; 281 : 36-7.

${ }^{2}$ Thomas WEG. Functional changes in acid secretion produced by duodeno-gastric reflux. Gut 1980; 21, 413-7.

${ }^{3}$ Thomas WEG. Serum gastrin levels in duodenal reflux and the control state. Gut 1979; 20: A918.

${ }^{4}$ Brazeau P, Vale W, Burgus R, et al. Hypothalamic polypeptide that inhibits the secretion of immunoreactive pituitary growth hormone. Science 1973; 179: 77-9.

${ }^{5}$ Polak JM, Pearse AGE, Grimelius L, Bloom SR, Arimura A. Growth-hormone release-inhibiting hormone in gastro-intestinal and pancreatic ' $D$ ' cells. Lancet $1975 ; 1: 1220-2$.

${ }^{6}$ Konturek SJ. Somatostatin and the gastrointestinal secretions. Scand J Gastroenterol 1976; 11 : 1-4.

${ }^{7}$ Elde R, Hokfelt T, Johansson O, Schultzberg M, Effendic S, and Luft R. Cellular localisation of somatostatin. Metabolism 1978; 27 : 1151-9.

'Barros D'Sa AAJ, Bloom SR, Baron JH. Direct inhibition of gastric acid by growth-hormone releaseinhibiting hormone in dogs. Lancet 1975; 1: 886-7.

${ }^{9}$ Vatn MH, Schrumpf E, Hanssen KF, Myren J. The effect of somatostatin on pentagastrin stimulated gastric secretion and on plasma gastrin in man. Scand $J$ Gastroenterol 1977; 12: 833-9.

${ }^{10}$ Konturek SJ, Tasler J, Cieszkowski M, Coy DH, Schally AV. Effect of growth-hormone release-inhibiting hormone on gastric secretion, mucosal blood flow, and serum gastrin. Gastroenterology 1976; 70: 737-41. 
${ }^{11}$ Gustavsson S, Lundqvist G. Antral somatostatin and gastrin release. VIth World Congress of Gastroenterology $1978 ; 62$.

${ }^{12}$ Kobayashi S, Fujita T. Emiocytotic granule release in the basal-stimulated cells of the dog induced by intraluminal application of adequate stimuli. In: Fujita T, ed. Gastro-entero-pancreatic endocrine system. Tokyo: Igaku Shoin, 1974: 49-58.

${ }^{13}$ Arimura A, Coy DH, Chihara M et al. Somatostatin. In Bloom SR. ed. Gut hormones. New York: Churchil Livingstone, Longman Inc, 1978: 437-45.

${ }^{14}$ Schusdziarra V, Harris V, Conlon JM, Arimura A, Unger R. Pancreatic and gastric somatostatin release in response to intragastric and intraduodenal nutrients and $\mathrm{HCl}$ in the dog. J Clin Invest 1978; 62: 509-18.

${ }^{15}$ Arimura A, Lundqvist G, Rothman J. et al. Radio- immunoassay of somatostatin. Metabolism 1978; 27:1139-44.

${ }^{16}$ Konturek SJ. Pharmacological inhibition of gastric secretion and the treatment of peptic ulcer. Rev. Esp. Enferm Apar Dig 1978; 55-70.

${ }^{17}$ Couzigou P, Robein MJ, Salmon R, Dubrasquet M, Bonfils S. Inhibition by somatostatin and neurotensin of the histamine-stimulated gastric secretion. Gastroenterology 1977; 72 : 1156.

${ }^{18}$ Schusdziarra V, Dobbs RE, Harris V, Unger RH. Immunoreactive somatostatin levels in plasma of normal and alloxan diabetic dogs. FEBS Lett 1977; 81 : 69-72.

${ }^{19}$ Schusdziarra V, Rouiller D, Harris V, Unger RH. Gastric and pancreatic release of somatostatin-like immunoreactivity during the gastric phase of a meal. Diabetes 1979; 28: 658-63. 